\title{
ESTUDI DE CAS SOBRE PERSPECTIVES DE GĖNERE EN ELS DEBATS VIRTUALS
}

\author{
Albert GRAs MarTí \\ Universitat d'Alacant \\ ElizABETH MORA TORRES Y Miguel L. LÓPEZ \\ SAEF-CI \\ ÀGUEDA GRAS-VELÁZQUEZ \\ EUN, European Schoolnet
}

Recibido: 29/06/2009

Aceptado: 01/09/2009

\section{Introducció}

La utilització de les Tecnologies de la Informació i la Comunicació (TIC) en el procés d'ensenyament/aprenentatge (E/A) planteja reptes urgents i necessitats formatives, i és un dels majors desafiaments actuals del sistema educatiu ${ }^{1}$. Lobjectiu ha passat de ser «aprendre informàtica» a «aprendre utilitzant les eines informàtiques» en un context on les TIC ajuden en el procés d'E/A, i serveixen també com a vehicle de comunicació i d'intercanvi.

Una eina eficaç per a la innovació docent són els entorns de gestió d'aprenentatges, com ara l'aula virtual Moodle de tic@'t. A més a més, els cursos de tipus interdisciplinari i de divulgació científica permeten aprenentatges transversals dels alumnes, així com el desenvolupament de competències i destreses que són bàsiques des d'un nou enfocament del procés d'ensenyament/ aprenentatge orientat en el marc de l'espai europeu d'educació superior. Però hi ha poca recerca sobre com fer el tractament de la diversitat en aules no presencials, especialment pel que fa a diferències de gènere. En aquesta línia

1. FrASER, Barry J. i TOBIN, Kenneth G. (Eds.). International Handbook of Science Education. Londres, Kluber Academic Publishers, 1998, p.23.

Feminismo/s 14, diciembre 2009, pp. 71-86 
podem esmentar treballs sobre el paper de la dona en el món digital ${ }^{2}$, i s'han de reavaluar estudis que es van fer en entorns no digitals ${ }^{3}$. Un estudi recent demostra que tot i que les dones tenen bones destreses informàtiques, encara eviten les carreres tècniques en gran mesura ${ }^{4}$.

Les eines típiques que té un entorn virtual d'aprenentatge (EVA) avui dia inclouen un lloc web per al lliurament del material d'aprenentatge i per a les tasques de l'estudiantat, eines de comunicació, tests de diversos tipus ${ }^{5}$, i el registre de les activitats de l'estudiant. Amb l'aparició d'entorns tipus EVA de codi lliure i cada vegada més sofisticats, que permeten dissenyar i impartir cursos i fer activitats docents en línia ${ }^{6}$, la recerca en l'aplicació de les TIC a l'E/A s'està desplaçant dels aspectes tecnològics (que ara són cada vegada més estàndards) als continguts dels materials i a les relacions entre els estudiants $i$ d'aquestos amb el tutor ${ }^{7}$. Per exemple, es troben diferències entre modalitats d'ensenyament presencials o no presencials ${ }^{8}$. En particular, la investigació de les diferències de gènere en la manera de treballar en entorns acadèmics i en els resultats del procés d'E/A són de fa temps un camp important de recer-

2. Rubio, $M^{a}$ Cruz. «La imagen virtual de la mujer. De los estereotipos tradicionales al ciberfeminismo». Feminismos/s, no 2 (2003), pp. 167-182; HufFaKER, David A. i CALVERT, Sandra L. "Gender, identity, and language use in teenage blogs». Journal of ComputerMediated Communication, vol. 10, $\mathrm{n}^{\mathrm{o}} 2$ (2005), <http://jcmc.indiana.edu/vollo/issue2/ huffaker.html>, consultat el 12-01-06.

3. SADLER-SMITH, Eugene. «Approaches to Studying: age, gender and academic performance». Educational Studies, vol. 22 (1996), pp. $367-379$.

4. <http://newsroom.cisco.com/dlls/2009/prod_062409b.html>, consultat el 27-06-2009.

5. GRAS-MARTí, Albert et al. «La evaluación, como ejemplo de integración de las TIC en la enseñanza». Comunicación y pedagogía, no 190 (2003), pp. 46-49; GRAS-MARTí, Albert et al. «Revision of prerequisites: ICT tools». AEQ-Academic Exchange Quarterly, vol. 7, $\mathrm{n}^{\circ} 3$ (2003). <http://rapidintellect.com/AEQweb/redpast.htm>, consultat el 25-06-06.

6. Gras-MarTí, Albert i CANO-VILlalba, Marisa. «Física i Ensenyament, Un entorn virtual per a l'ensenyament / aprenentatge». Eines, $n^{\circ} 18$ (2000), pp. 61-66. <http://www.ua.es/ $\mathrm{dfa} / \mathrm{agm} / \mathrm{recerca}$-sci.html>, consultat el 15-08-2008; MILACHAY, Vicente Y. i GRAS-MARTí, Albert. «Instalación y gestión de plataformas virtuales para el desarrollo de Proyectos Escolares de Ciencia Internacionales». En J. Mendoza i M.A. Fernández (coords.) Educación, Enerxía e Desenvolvemento Sostible. Santiago de Compostela, ICE Universidade de Santiago de Compostela, Colección Informes e Propostas n ${ }^{\circ}$ 18, 2006, pp. 407-424.

7. LIJNSE, Piet L. «Didactics of science: the forgotten dimension of science education research». En R. Millar, J. Leach i J. Osborne (Eds.). Improving science education. The contribution of research. Buckingham, Open University Press, 2000, pp. 308-326.

8. Gras-Martí, Albert, Cano-Villalba, Marisa i Cano, Carlos. "Cursos de TIC per al professorat: anàlisi comparatiu de les modalitats presencial, semipresencial i no presencial». REEC. Vol. 3, no 1 (2004), pp. 1-25 <http://www.saum.uvigo.es/reec/volumenes/ volumen3/Numerol/Art3.pdf>, consultat el 12-03-2009. 
$\mathrm{ca}^{9}$. Recentment s'ha eixamplat el camp a l'estudi de qüestions de gènere en l'aplicació de les TIC en l'ensenyament no presencial (NP) ${ }^{10}$. El present treball és una contribució en aquesta línia de recerca.

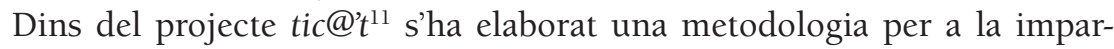
tició de cursos d'introducció i d'actualització en eines TIC, així com cursos de caràcter interdisciplinari ${ }^{12}$. El format de treball és NP i s'ofereix a tota la comunitat educativa. Primer descriurem l'aula tic@'t com a instrument per a la innovació docent, la metodologia de treball en què es basa i donarem unes breus pinzellades sobre l'avaluació d'aquestes. Tot seguit analitzarem, des de la perspectiva de gènere, els debats virtuals que es produeixen en cursos de caràcter interdisciplinari i amb participants que pertanyen a carreres $\mathrm{i}$ a col.lectius diferents.

\section{Metodologia docent en el projecte tic@’t}

Dins del projecte tic@'t (fig.1), s'ha dissenyat una metodologia per a la impartició dels cursos que atenen demandes de formació i d'actualització detectades en la Universitat d'Alacant (UA) i en centres educatius de secundària de la comarca. La majoria dels cursos de lliure configuració o d'extensió universitària oferits per la UA s'imparteixen en format presencial (d'horaris rígis i amb aules de capacitat limitada), i això limita, per tant, la formació a un nombre molt reduit de professors i d'alumnes. El model de formació contínua desenvolupat per tic@t ofereix una sèrie de cursos que es poden iniciar en qualsevol moment de l'any. Totes les sessions de treball, així com el procés d'inscripció als cursos, i les enquestes d'avaluació, es desenvolupen de manera NP via la plataforma educativa Moodle de tic@'t.

9. RICHARDSON, Helen J. i FRENCH, Sheila. «Education on line: What's in it for Women?», en E. Balka i R. Smith (eds). Women Work and Computerization: Charting a course for the future. Vancouver, BC, 2000, pp. 212-216.

10. MCSPORRAN, Mae i YounG, Stuart. «Does Gender Matter in Online Learning?». 4th Annual LTSN-ICS Conference, NUI Galway, 2001. <http://hyperdisc.unitec.ac.nz/research/ ALTJpaper_9.pdf>, consultat el 8-06-2009; AGOSTO, Denise E. «A study of girl's and young women's electronic information design and content preferences». Tesis Doctoral, Douglass College, USA, 2002. <http://girlstech.douglass.rutgers.edt/gt_summary. html>, consultat el 15-06-2009; DAHLBERG, Lincoln. «The Internet and Democratic Discourse: Exploring The Prospects of Online Deliberative Forums Extending the Public Sphere, Information». Communication \& Society, vol.4 (2001), pp. 615 - 633.

11. <http://ticat.org>, consultat el 17-10-2009.

12. MORA, Elizabeth. «Anàlisi de les enquestes finals de cursos tic@it-CED». (En vies de publicació).

Feminismo/s 14, diciembre 2009, pp. 71-86 
Figura 1. Pàgina d'entrada del projecte tic@'t

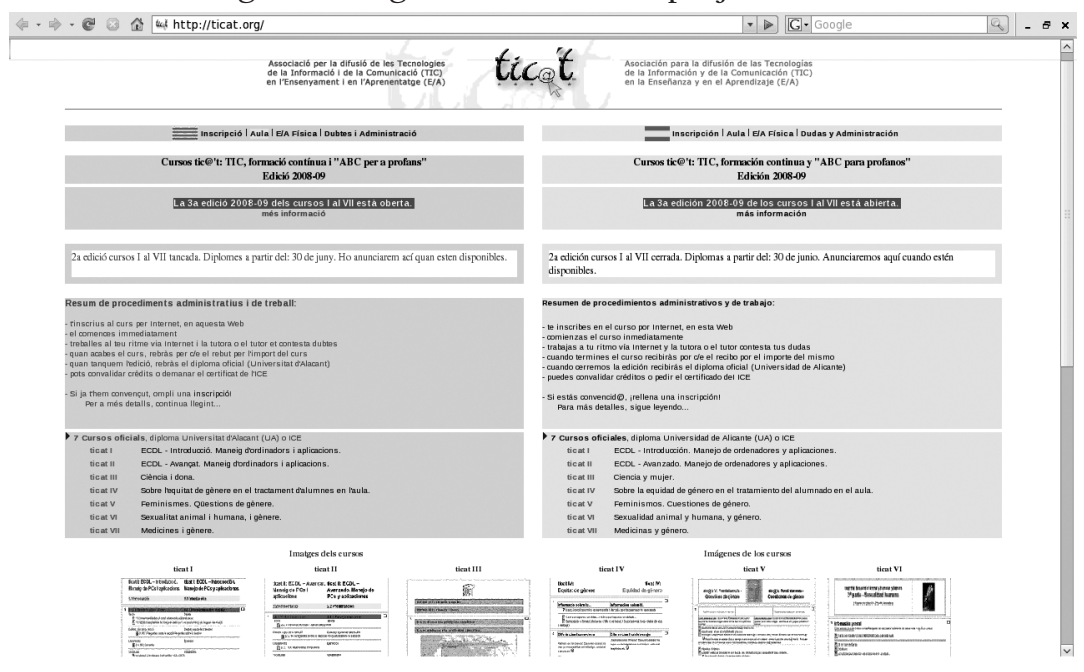

Aquest entorn de treball facilita la interacció, en un mateix espai educatiu, entre diferents col-lectius del món educatiu que no solen coincidir en un mateix ambient d'aprenentatge: l'alumnat, el PAS (Personal d'Administració i Serveis) i professorat de nivells diversos (des de primària fins la universitat), i fins i tot familiars i amics d'aquests ${ }^{13}$.

Una de les característiques principals que ha de tenir la interfície és que l'estructura interna del curs es manifeste ordenadament i clara a l'estudiant, per a evitar-li ansietat i un baix aprofitament dels materials ${ }^{14}$. Aquestes característiques les satisfan les plataformes modernes i l'aula tic@t' (fig.2). La millora contínua i gratuita de la plataforma és un dels majors avantatges de Moodle.

13. Els components de l'aula s'han descrit en: BOADA, Oswaldo, T. et al. «Estrategias de formación en TIC del profesorado de un centro: experiencias piloto para un Departamento de Recursos Tecnológicos». Quaderns Digitals, nº. 39 (2005). <http://pulsar.ehu. es/pulsar/documentacion/publicacion_pulsar.2005-06-21.6545349213/es>, consultat el 23-03-2007; Gras-MarTí Albert i CANO-Villalba, Marisa. «Debats i tutories com a eines d'aprenentatge per a alumnes de ciències: anàlisi de la integració curricular de recursos del campus virtual». Enseñanza de las Ciencias, vol. 23, n 2, (2005), pp. 167-180.

14. Mcanally-Salas, Lewis i Armijo De Vega, Carolina. «La estructura de un curso en línea y el uso de las dimensiones del aprendizaje como modelo instruccional». Revista Iberoamericana de Educación (2001), <http://www.campus-oei.org/revista/deloslectores/McAnally.PDF>, consultat el 1-09-2008. 
Figura 2. Entrada a l'aula del projecte tic@'t

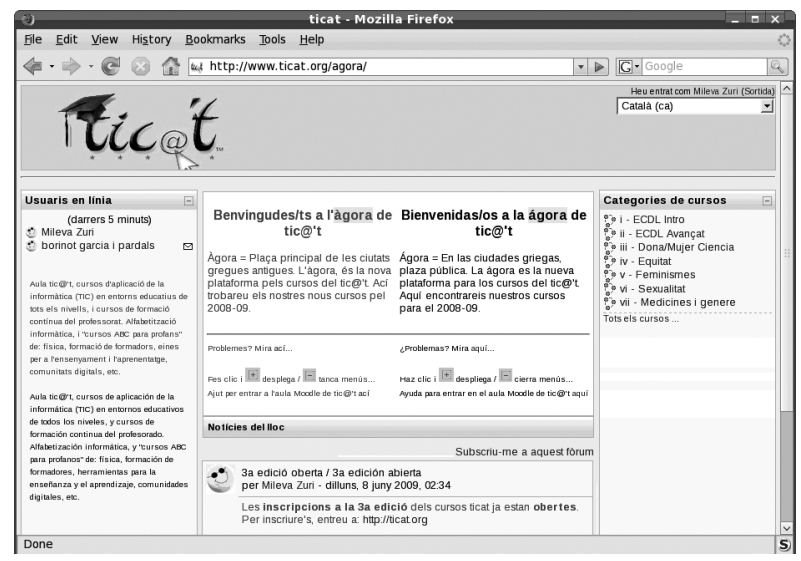

La metodologia de treball es basa en tres pilars: la tutorització, la no presencialitat i el treball al ritme de l'alumne. La metodologia tic@'t permet una major eficiència dels esforços formatius; l'alumnat dels cursos en línia configura un ús més eficient del temps, no només pel que fa a l'estalvi de desplaçaments cap a l'aula del curs, sinó perquè els alumnes més avançats redueixen el temps que passen seguint instruccions o discussions sobre aspectes que ja coneixen. Els estudiants avancen al seu propi ritme i en els horaris que més els convé. La flexibilitat és un element essencial. La funció tutorial en cursos NP té una rellevància especial i es basa en:

- Fòrums de debat.

- Correu electrònic tutor-alumne.

- Llistes de FAQ (preguntes freqüents).

- Enquestes periòdiques sobre la marxa del curs i l'opinió de l'alumnat: nivell de participació, temes més importants que es tracten en els debats, etc.

- Qüestionaris d'avaluació del curs, que inclouen aspectes metodològics, conceptuals, de tutorització i de satisfacció personal.

- Anàlisis i comentaris de totes les tasques que l'alumne lliura al llarg del curs, per part dels tutors.

Les discussions i les tutories en línia reforcen també l'autoestima dels estudiants quan reben una retroalimentació ràpida i adequada per part del tutor, que els estimula a contribuir amb les seues idees, opinions o qüestions. D'aquest tema i, en particular, de les diferències de gènere que s'hi aprecien en els debats en línia, parlarem en l'estudi de cas següent. 


\section{Estudi de cas: diferències de gènere en els debats en línia}

Es té la percepció, basada en dades estadístiques, que la Informàtica és una matèria amb esbiaix de gènere, escassa de dones. Dades de l'INE ${ }^{15}$ sobre l'ús d'Internet mostren que a l'estat espanyol les dones la fan servir un $9 \%$ menys que els homes ( $27 \%$ front al 36\%), ben per sota de la mitjana europea: en la UE de 15 països, les xifres són, respectivament, 36\% front al 46\%. Però això no significa, necessàriament, que l'aprenentatge en línia, que fa servir les TIC, seguesca la mateixa tendència. Cada vegada hi ha més evidència que assenyala que, ben al contrari, els mitjans d'E/A digitals poden, fins i tot, afavorir les dones davant els homes. Les causes que s'apunten són múltiples i diverses, com ara la major timidesa femenina a expressar opinions en públic (especialment en temes cientificotècnics), la preferència per entorns que faciliten la comunicació i l'intercanvi d'experiències, la disponibilitat de materials en format multimèdia i hipertextual, les situacions familiars o laborals, la capacitat de treballar de manera regular, la capacitat de connectar-se i desconnectar-se d'una tasca en breus instants, etc. És a dir, es tracta de característiques típicament associades al món femení, i que sembla que afavoreixen aquest gènere en la interacció via la Web, però aquesta afirmació cal quantificar-la amb recerques especialitzades.

Hi ha encara pocs estudis sobre gènere i aprenentatge en línia, en particular per a assignatures de nivell universitari i cursades en entorns NP. S'ha trobat, per exemple, que l'ús de les TIC pot ajudar a eliminar diferències de gènere en la fracció d'homes/dones matriculades en carreres tècniques ${ }^{16}$. Però cal investigar altres aspectes del procés d'ensenyament/aprenentatge en línia.

El nostre treball se centra en l'anàlisi d'una assignatura oferida per tic@'t, i ací tractarem un aspecte concret, la forma de participació en els fòrums de debat del curs. Es tracta del curs «El paper de les dones en la ciència i en la tècnica». Aquest curs es desenvolupa en col-laboració amb el Centre d'Estudis sobre la Dona, de la Universitat d'Alacant. En la secció següent formularem les qüestions de recerca; a continuació descriurem la metodologia i els dis-

15. INE. Encuesta sobre equipamiento y uso de tecnologías de información y comunicación en los hogares, Año 2004, <http://www.ine.es/prensa/np362.pdf>, consultat el 12-03-2007.

16. GFRERER, M. i PAusChENWEIN, J. «Is the change from traditional teaching methods to ICT-based methods going to attract more female students to study engineering? An analyse of ICT-based lectures at the Technikum Joanneum». International Seminar of SEFI Working Groups in ICT and Women in Engineering, Oulu, Finlandia, 16-17 de mayo de 2002. <www.fh-joanneum.at/ca/cd/yuj/>, consultat el 19-09-2009. 
senys emprats per obtenir-ne dades, i clourem amb una anàlisi dels resultats i les conclusions de l'estudi de cas $^{17}$.

\section{Pros i contres del model d'e/a de tic@'t}

Laprenentatge via la Web requereix una disciplina elevada per a treballar de manera regular, consegüent i profitosa. Una manera de facilitar-ho és mitjançant grups de treball que collaboren conjuntament en les tasques i asseguren l'èxit del grup. Però aquesta modalitat és més difícil d'implementar en cursos de lliure elecció i de format NP on, a més a més, l'alumnat prové de carreres diverses de tot el Campus i de fora. Els desavantatges (en termes de manca d'esperit de grup) que podria suposar l'entrada i eixida constant d'alumnes en el curs, pel model d'inscripció que practica tic@'t, i la diferent intensitat de dedicació de l'alumnat del curs, es veuen compensats per factors positius que es donen en la metodologia tic@'t $t^{18}$, en particular pel que fa als fòrums de debat, aspecte principal del qual parlarem ací. En efecte, en els debats asíncrons i entre alumnes d'edats diferents s'observa que:

1) El nombre d'alumnes amb què interacciona un/a alumne/a determinat/da és major i més variat, perquè pot aprofitar allò que han fet i dit companyes i companys del curs en moments anteriors. (Fins i tot si un/a alumne/a ha acabat el curs, té l'oportunitat de continuar participant en els debats del curs: aquesta opció és absent, òbviament, en cursos que es fan en modalitat purament presencial).

2) Lalumne més veterà en el curs pot tornar enrere a temes del curs ja treballats, animat per les contribucions fresques (debats o treballs) d'alumnes que s'hi incorporen en qualsevol moment.

3) La possibilitat, que aprofiten professores i professors (de secundària, principalment, i algun PAS de la Universitat), de participar en els cursos tic@'t fa que l'estudiantat universitari puga interaccionar formalment i debatre amb uns col-lectius amb els quals no té contacte normalment. Aquesta oportunitat d'interacció es valora molt positivament entre l'alumnat dels $\operatorname{cursos}^{19}$.

17. En aquest treball presentarem els resultats més significatius de l'estudi. Els continguts detallats de les enquestes i la seua quantificació es publicaran en un altre treball: MORA, Elizabeth. «Anàlisi de les enquestes finals de cursos tic@t-CED». (En vies de publicació).

18. BOADA, Oswaldo, T. et al. Op cit.

19. MORA, Elizabeth. Op cit.

Feminismo/s 14, diciembre 2009, pp. 71-86 


\subsection{Qüestions de recerca}

Aprofitarem, per tant, la metodologia tic@t per a analitzar la influència del factor gènere en els debats virtuals. En concret, analitzem els processos de comunicació que s'hi menen, en escenaris d'aprenentatge virtual, i que estan facilitats per diversos tipus de comunicació síncrona i asíncrona. Les preguntes que volem respondre en aquest estudi són les següents:

- ¿ ¿Hi ha diferències de gènere en...

1) la manera de treballar en un curs NP?

2) l'actitud d'estudiantes i d'estudiants davant d'un espai virtual d'aprenentatge?

3) l'expressió d'opinions i la participació en debats?

4) la sensació d'aprenentatge de l'alumnat?

- Volem mesurar, també, la influència del gènere sobre...

5) el control que té cada estudiant sobre el seu aprenentatge.

6) el grau en què l'estudiant percep que té accés a l'acció tutorial i en rep suport.

7) en quina mesura se senten còmodes estudiantes i estudiants del curs en expressar el seu punt de vista, i senten que les seues opinions són escoltades i valorades per la resta d'estudiantes/ts.

8) el resultat final del curs, la profunditat del coneixement que es percep que es té i l'oportunitat de reflexionar sobre el que s'ha aprés.

\subsection{Metodologia: disseny i recollida de dades}

La mostra és de 317 alumnes que han participat al llarg de dues edicions del curs, dels quals 139 eren homes. Les dades per a aquest estudi s'han arreplegat amb els instruments analítics següents:

- Prospeccions (enquestes) pre i postcurs, que emplena tot estudiant inscrit a un curs tic@t. Els qüestionaris cerquen respostes qualitatives i quantitatives.

- Un qüestionari sobre les quatre primeres qüestions de recerca enunciades adès. L'estudiant ha de respondre cada conjunt de qüestions dues vegades, una en relació al curs que tractem i l'altra en relació amb la seua experiència amb altres «cursos presencials de què s'haguera matriculat». Hem fet servir escales de Likert de cinc punts: 1-totalment en desacord, 2-desacord, 3-neutre, 4-d'acord, 5-totalment d'acord. 
- Entrevistes personals presencials, amb uns pocs alumnes del curs, seleccionats aleatòriament.

- Entrevistes semiestructurades als tutors dels cursos.

- Anàlisi dels continguts de les contribucions. A més d'investigar com participen estudiantes i estudiants en discussions en línia en cursos universitaris, hem tractat d'esbrinar si hi ha diferències de gènere en termes de nombre de contribucions i el seu caràcter. Hem separat les contribucions substantives (les directament relacionades amb el tema del debat) de les no substantives (no directament relacionades amb els continguts del debat proposat). S'ha avaluat també la netiquette (qüestions d'etiqueta en ambients de xarxa), l'efectivitat dels textos que redacten els estudiants (manca d'ambigüitats, per exemple) i el grau de relació amb el tema objecte del debat.

Com a mesura d'aprenentatge hem fet servir la percepció de l'estudiant/a, en lloc d'avaluacions independents (com ara els resultats de tests), perquè en molts cursos de lliure configuració no cal més que l'assistència per a aprovarlos; i tot i que en alguns cursos presencials s'han de lliurar treballs o memòries finals (com també en el nostre curs), aquests treballs no comporten qualificació, llevat d'un «apta/e», i no ens serveixen per discriminar les tasques que hi fan els estudiants.

\subsection{Resultats i discussió}

Lanàlisis del procès d'E/A en entorns NP i la influència de qüestions de gènere es presta a diferents tipus de preguntes d'investigació. Presentem ací els resultats de la recerca relacionada amb els fòrums de debat.

En el curs tic@'t que hem analitzat el nombre de contribucions als debats és, típicament, un 15\% major en el cas de les dones (una vegada corregides les dades per la diferència d'homes/dones en la matrícula en el curs). A més a més, es pot veure que, en general, les dones es comuniquen de manera molt més precisa i simple que els homes, és a dir, si no tenen una resposta clara a la qüestió no dubten a expressar-ho.

Les anàlisis dels debats mostren que, en termes generals, tant homes com dones fan contribucions substantives i no substantives a les discussions. Tant per a uns com per a les altres la major quantitat de contribucions eren reactives: es feien en resposta i en reacció a d'altres contribucions. No hi ha diferències significatives pel que fa al gènere en les contribucions substantives als debats. Però sí que es troben en les dones (en un 20\% superior als homes) major nombre de contribucions no substantives (comentaris d'ànim, frases per 
«connectar», etc.). Aquests resultats són semblants als de Davidson-Shivers, Morris i Sriwongkol ${ }^{20}$. Tan sols hem trobat algunes diferències amb aquests autors en el fet que els homes plantegen en els debats un 16\% més de qüestions «noves» que les dones, és a dir, són més proactius que les dones en els debats oberts.

Aparentment, en un entorn virtual no tenen el mateix pes (o no s'hi apliquen) les regles socials (implícites i culturals) que animen els homes a ser més assertius i a expressar les seues opinions, i a les dones a ser més callades. En efecte, s'ha trobat en l'anàlisi de les enquestes i les converses amb els alumnes que, com també reporten Anderson i Haddad ${ }^{21}$, un avantatge de les discussions en línia és que es pot reflexionar i cercar via Internet, per exemple, informació que done suport a una opinió que volem expressar. Per a un $30 \%$ de les alumnes i un $19 \%$ dels alumnes enquestats i entrevistats aquesta és un avantatge dels cursos NP. Com que la reflexió és un indicador de pensament d'alt nivell (d'habilitats cognitives de nivell elevat), aquella part de l'alumnat que prefereix reflexionar abans d'emetre una opinió sol ser el mateix que prefereix els debats que es desenvolupen en un entorn NP.

Les dades del nostre estudi mostren clarament que les dones fan servir en major mesura aquests recursos d'E/A NP. En efecte, mentre que el percentatge d'estudiantes matriculats a la UA supera al d'estudiants masculins en un 5.2\% ${ }^{22}$, en els cursos NP de tic@'t el percentatge de dones és un 25\% superior al d'homes. Aquesta major inscripció femenina en cursos de tic@'t és consistent amb el fet que, a la UA, també les dones superen en un 23.72\% als homes en matrícules en «altres estudis», diferents dels de primer i segon cicle universitari.

Un dels ítems de l'enquesta esmentada en l'apartat de Metodologia demana l'alumnat que compare el cursos presencials i no presencials que haja fet per a obtenir crèdits de lliure configuració. La pregunta es fa tant abans d'iniciar com després d'acabar un curs NP, per veure si hi ha consistència en les respostes dels alumnes. En el $95 \%$ dels casos les respostes dels alumnes van ser consistents. La taula 1 mostra els resultats de l'anàlisi de les respostes

20. DAVIDSON-SHIVERS, Gayle, MorRIS, Samantha, SRIWONGKOL, Tuangrat. «Gender differences: are they diminished in online discussions?». International Journal on e-learning, vol. 2, no 1 (2003), pp. 29-36. <http://dl.aace.org/1155l>, consultat el 02-02-2009.

21. ANDERSON, David M. i HADDAD, Carol J., «Gender, Voice and Learning in Online Course Environments», JALN vol. 9, $\mathrm{n}^{\mathrm{o}} 1$ (2005). <http://www.sloan-c.org/publications/ jaln/v9n1/v9n1_anderson.aspe>, consultat el 12-04-2009.

22. Universitat d'Alacant. La UA en xifres. Matrícula en el curs 2008-09, pel tipus d'estudis i per sexe. <http://www.ua.es/va/servicios/upec/ua_cifras/matricula.html>, consultat el 19-10-2009. 
de les alumnes. S'hi veu que les dones tenen major percepció d'aprenentatge en cursos NP que en P (presencials). També, com ja s'ha dit, les estudiantes expressen les opinions de manera més freqüent en cursos NP que en P, i aquesta contribució resulta en una major sensació d'aprenentatge. El recolzament i la presència de/la tutor/a contribueix directament a aquella sensació, a través de l'ajut que reben els estudiants. Aquesta acció tutorial és valorada per les alumnes en un $19 \%$ més que els alumnes masculins (és a dir, la mitjana de les respostes a la pregunta sobre «Ajut i suport de/la tutor/a» és 3.8 per als alumnes masculins i un 4.6 per a les alumnes).

Taula 1: Anàlisi dels qüestionaris sobre el curs (resultats per a les alumnes).

\begin{tabular}{|c|c|c|c|}
\hline & Mitja & $\begin{array}{l}\text { Likert: } \\
5\end{array}$ & Opinions representatives \\
\hline \multirow{2}{*}{$\begin{array}{l}\text { Control sobre } \\
\text { l'aprenentatge }\end{array}$} & $\mathrm{P}$ & 2,2 & El curs era molt poc dinàmic i massa rígid. \\
\hline & NP & 3,4 & $\begin{array}{l}\text { El curs era suficientment flexible. } \\
\text { Notava que podia aprendre al meu ritme. }\end{array}$ \\
\hline \multirow{2}{*}{$\begin{array}{l}\text { Autorepressió de } \\
\text { la participació } \\
\text { (vergonya) }\end{array}$} & $\mathrm{P}$ & 4,3 & $\begin{array}{l}\text { La preocupació per les opinions de companys/ } \\
\text { es afecta l'expressió dels meus punts de vista. }\end{array}$ \\
\hline & NP & 2,5 & $\begin{array}{l}\text { No tenia por d'expressar opinions contràries, } \\
\text { com hauria ocorregut en un curs P. }\end{array}$ \\
\hline \multirow{2}{*}{$\begin{array}{l}\text { Ajut i suport de/la } \\
\text { tutor/a }\end{array}$} & $\mathrm{P}$ & 1,8 & $\begin{array}{l}\text { (No es va plantejar la figura d'un/a tutor/a en } \\
\text { cap curs P). }\end{array}$ \\
\hline & NP & 4,6 & $\begin{array}{l}\text { Tenia accés permanent al/la tutor/a del curs. } \\
\text { Notava la presència dels tutors en cada activitat } \\
\text { meua en el curs. }\end{array}$ \\
\hline \multirow[b]{2}{*}{ Expressió d'opinió } & $\mathrm{P}$ & 2 & Gairebé mai la vaig expressar. \\
\hline & NP & 3,9 & $\begin{array}{l}\text { Em sentia còmoda en expressar els meus punts } \\
\text { de vista sobre els temes plantejats. } \\
\text { Els continguts i el format del curs permetia que } \\
\text { expressàrem i debatérem opinions múltiples } \\
\text { sobre cada qüestió que s'hi plantejava. } \\
\text { Tenia major llibertat per triar les paraules amb } \\
\text { què expressar com em sentia sobre els temes del } \\
\text { curs. }\end{array}$ \\
\hline \multirow[b]{2}{*}{$\begin{array}{l}\text { Percepció } \\
\text { d'aprenentatge }\end{array}$} & $\mathrm{P}$ & 2,3 & \begin{tabular}{|l}
$\begin{array}{l}\text { Els continguts no em resultaven massa } \\
\text { interessants. }\end{array}$ \\
\end{tabular} \\
\hline & NP & 4,3 & $\begin{array}{l}\text { Les activitats del curs m'animaven a reflexionar } \\
\text { sobre els continguts del curs abans de compartir } \\
\text { els meus pensaments. } \\
\text { He aprés molt en el curs, però també he treballat } \\
\text { molt, i de fet molt més que en qualsevol dels } \\
\text { cursos P que he fet. }\end{array}$ \\
\hline
\end{tabular}

$\mathrm{P}=$ presencial $/ \mathrm{NP}=$ no presencial . 
Per tant, hi ha diferències de gènere en l'extensió amb què l'alumnat percep l'ajut del professorat. Les dones perceben més ajut en cursos NP que els homes. Aquest fet es pot deure al fet que les estudiantes estan més disposades en cursos NP a sol-licitar ajut del/a tutor/a que en les tutories cara a cara dels cursos P, especialment en carreres tècniques, on el professor és encara majoritàriament masculí.

També hem observat algunes evidències (en entrevistes personals, o en comunicacions privades per correu electrònics) que indiquen que les dones també trien els cursos NP en línia en major proporció com a forma de millorar el seu Currículum Vitae (CV), i per tal d'experimentar un EVA de formació continuada, de cara a trobar feina més fàcilment en el futur. Per exemple, les qüestions de resposta oberta de les enquestes indiquen que la inclussió en el CV cursos de temàtica de gènere o d'informàtica aplicada pot ajudar a l'obtenció de treballs a temps parcial en el futur, o treballs que es puguen fer des de casa.

Com confirmen les anàlisis de les dades sobre hores de connexió a l'aula, en els cursos NP es reprodueixen els patrons de gènere dels cursos $\mathrm{P}$, pel que fa al comportament $\mathrm{i}$ hàbits de treball $^{23}$ : les dones tendeixen a progressar tranquil-lament al llarg del curs, seguint les instruccions i fent les tasques regularment, mentre que els homes van a batzegades i tenen períodes de no participació més prolongats. Es constata, en les dades que proporcionen els registres de l'aula sobre l'evolució temporal de les activitats de l'alumnat, que més dones que homes presenten dins dels terminis establerts els treballs que requereix el curs; i, a la vista dels comentaris dels tutors en les entrevistes semestrals que els hem fet, els treballs de les alumnes són de major qualitat globalment. Com també s'ha vist en altres estudis ${ }^{24}$, això es pot deure a que els homes tenen un excés de confiança, especialment en entorns digitals i ajornen les tasques i les duen a terme amb més rapidesa i menys cura.

S'ha preguntat també l'alumnat quin era el millor moment del dia per a treballar el curs NP. Les respostes estan correlacionades amb l'edat de l'alumna/e i la situació laboral o familiar que té: la fracció de l'estudiantat més madur sol dir «de nit i tard», o «de bon matí» (que és quan no hi ha familiars al voltant $o$ bé s'han acomplert les tasques domèstiques), i l'alumnat més jove sol dir que

23. Severiens, Sabine E., Ten Dam, Geert T. N. «Gender differences in learning styles: A narrative review and quantitative meta-analysis». Higher Education, vol. 27, $\mathrm{n}^{\circ} 4$ (2004), pp. 487-501.

24. Lim Yuen Lie, Lisa-Angelique i Cheong, Emil. «How Do Male and Female Students Approach Learning at NUS?». CDTL Brief, vol. 7, $\mathrm{n}^{\circ} .1$ (2004). <http://www.cdtl.nus. edu.sg/brief/v7nl /default.asp>, consultat el 19-10-2009. 
estudia «en qualsevol moment» del dia. Aquestes dades es poden certificar en comprovar els registres digitals de les seues activitats en l'aula: el patró de connexió a l'aula d'alumnes de menor edat és irregular, i amb una durada de connexió variable, amb tendència a ser sempre curtes en comparació amb l'alumnat de major edat.

La tutorització de cursos en línia, és a dir, l'ensenyament NP, presenta altres avantatges de gènere: les dones tenen, per educació i per realitat familiar i cultural, l'hàbit d'organitzar amb cura el dia a dia, i d'adaptar-se ràpidament als imprevistos i als canvis; les donen tenen, també, l'habilitat de fer malabarismes amb diverses tasques petites que aborden al mateix temps. Pot ser per aquestes raons les dones tenen avantatge de partida en entorns NP i asíncrons, i tenen l'habilitat adquirida de desenvolupar una flexibilitat cognitiva i estils d'estudi i d'aprenentatge particulars, que no tenen els homes ${ }^{25}$.

On s'hi fa sentir una diferència de gènere important de partida és en les expectatives d'estudiantes i estudiants sobre les seues capacitats abans d'encetar el curs. Destaca la manera tan dispar com es perceben homes i dones en relació amb les habilitats en entorns digitals: els homes creuen en major nombre que tenen suficient experiència en Internet i en el maneig d'hipertextos que les dones. Però el treball regular i intens és un factor molt important per a l'èxit en els cursos NP, i té major influència sobre l'èxit en el curs que les percepcions originals que es tinguen sobre coneixements de TIC aplicades a l'E/A. Aquesta realitat ve avalada pel fet que l'índex d'abandonament de cursos NP, tot i que és baix (un 15\% del total d'alumnes inscrits), és superior en un $25 \%$ en homes que en dones.

Com s'ha comentat abans, l'ensenyament NP té l'avantatge que les dones no han d'entrar en ambients dominats per la presència masculina (com ara cursos d'informàtica bàsica o avançada, o de divulgació científica). En les enquestes es declara que el $70 \%$ de les alumnes no s'hagueren inscrit en un curs amb el títol i continguts del curs, si fóra de tipus presencial.

\section{Conclusions}

Hem trobat, doncs, que els cursos NP tenen avantatges per a les alumnes, i per a les estudiantes més majors en comparació amb les de menor edat. Les dones es comuniquen millor que els homes en línia, és a dir, amb major facilitat i amb millor suport documental, i són més capaços d'organitzar-se i de

25. Aquests fets han estat assenyalats també per CAMPBELL, N. «Online learning for preservice teachers». Compùters in NZ Schools, 1997, pp. 21-24. <http://www.waikato.ac.nz/ education>, consultat el 02-05-2008.

Feminismo/s 14, diciembre 2009, pp. 71-86 
planificar el seu estudi. Les dones fan també les tasques de manera més eficient que els homes. Això ja s'ha constatat en altres àmbits i s'està començant a constatar també en l'àmbit de l'E/A NP i en línia.

En contrast, els estudiants masculins, i els de menor edat entre ells, estranyen més la disciplina que proporciona l'ensenyament presencial. L'èxit general del curs virtual depèn de l'estudiantat i de la seua actitud. Les habilitats bàsiques d'autoregulació i de gestió dels temps sembla que estan poc desenvolupades en el cas dels homes joves, especialment en comparació amb les dones. Això podria explicar que el percentatge de dones que acaben el curs NP siga superior al d'homes.

La presència constant de la tutora o del tutor en els cursos NP contribueix a una major percepció d'aprenentatge per als estudiants dels dos sexes en relació als cursos presencials. Però les estudiantes s'expressen més i amb major profunditat en entorns en línia que en els presencials. En general, en debats en línia l'estudiant/a pot fer preguntes sense el temor que companys i companyes l'estigmatitzen, però en temàtiques cientificotècniques són les dones les que més aprofiten aquest avantatge de la no presencialitat.

Una altra constatació clara és que en debats que prenen direccions que s'allunyen de la qüestió inicial, són els homes els que generalment provoquen aquestos desviaments. Les dones tendeixen a mantenir-se més centrades en el tema del debat.

És digna d'esment també la ironia que és dóna en l'E/A en línia. El procés d'E/A en la Web té dos efectes aparentment contradictoris: despersonalitza i individualitza la comunicació al mateix temps. Malgrat el fet que la interacció es produeix davant d'un ordinador i «a distància» i, com a conseqüència, cada alumna/e podria sentir aparentment gelor i aillament, en realitat l'alumne/a es pot sentir membre d'un collectiu, al mateix temps que se sent considerada/t personal i individualment, gràcies a la gran interacció i possibilitats d'intercanvi d'opinions i d'informacions que ofereixen els cursos NP. Aquest aspecte és més valorat en les enqueste pel col-lectiu femení.

En aquesta línia volem aportar, finalment, algunes conclusions de caire més general sobre la metodologia d'E/A tic@'t. Com a elements essencials del projecte destaquen la interdisciplinarietat, la interestamentalitat (alumnes, PAS i professors universitaris i de secundària) i la possibilitat de dur a terme investigació educativa com la present.

A més a més, la participació en cursos tic@'t té l'al-licient per a l'alumnat que li permet experimentar amb una metodologia de treball (la formació en línia) que, se suposa, l'acompanyarà la resta de la seua vida professional i laboral. En particular, propostes de cursos i de metodologia com els esmentats ací 
són d'interès per a aplanar el camí cap al sistema de crèdits europeus (el sistema ECTS), on la component NP del procés d'E/A cobra gran protagonisme.

\section{Referències}

AGOSTO, Denise E. "A study of girl's and young women's electronic information design and content preferences». Tesis Doctoral, Douglass College, USA, 2002. <http://girlstech.douglass.rutgers.edt/gt_summary.html>, consultat el 15-06-2009.

Anderson, David M. i Haddad, Carol J. "Gender, Voice and Learning in Online Course Environments». JALN, vol. 9, no 1 (2005). <http://www.sloan-c.org/ publications/jaln/v9n1/v9n1_anderson.asp>, consultat el 12-04-2009.

BOADA, Oswaldo, T. et al. «Estrategias de formación en TIC del profesorado de un centro: experiencias piloto para un Departamento de Recursos Tecnológicos». Quaderns Digitals, no 39 (2005). <http://pulsar.ehu.es/pulsar/documentacion /publicacion_pulsar.2005-06-21.6545349213/es>, consultat el 23-03-2007.

CAMPBEll, N. «Online learning for preservice teachers». Compùters in NZ Schools, (1997), pp. 21-24.<http://www.waikato.ac.nz/education>, consultat el 02-05-2008.

DAHLBERG, Lincoln. «The Internet and Democratic Discourse: Exploring The Prospects of Online Deliberative Forums Extending the Public Sphere, Information». Communication \& Society, vol. 4 (2001), pp. 615 - 633.

DAVIDSOn-SHIVERS, Gayle, Morris, Samantha i SRIWOngKOL, Tuangrat. «Gender differences: are they diminished in online discussions?». International Journal on e-learning, vol. 2, no 1 (2003), pp. 29-36. <http://dl.aace.org/11551>, consultat el 02-02-2009.

Fraser, Barry J. i TOBIn, Kenneth G. (Eds.). International Handbook of Science Education. Londres, Kluber Academic Publishers, 1998.

GFrerer, M. i PAuschenwein, J. «Is the change from traditional teaching methods to ICT-based methods going to attract more female students to study engineering? An analyse of ICT-based lectures at the Technikum Joanneum». International Seminar of SEFI Working Groups in ICT and Women in Engineering, Oulu, Finlandia, 16-17 de mayo de 2002. <www.fh-joanneum.at/ca/cd/ yuj/>, consultat el 19-09-2009.

Gras-MARTí, Albert i CANO-VILlalbA, Marisa. «Física i Ensenyament, Un entorn virtual per a l'ensenyament / aprenentatge». Eines, nº 18 (2000), pp. 61-66. <http://www.ua.es/dfa/agm/recerca-sci.html>, consultat el 15-08-2008.

- «Debats i tutories com a eines d'aprenentatge per a alumnes de ciències: anàlisi de la integració curricular de recursos del campus virtual». Enseñanza de las Ciencias, vol. 23, nº 2 (2005), pp. 167-180.

Gras-MARTí, Albert, Cano-Villalba, Marisa i CANO, Carlos. «Cursos de TIC per al professorat: anàlisi comparatiu de les modalitats presencial, semipresencial i 
no presencial». REEC, vol. 3, no 1 (2004), pp. 1-25 < http://www.saum.uvigo. es/reec/volumenes/volumen3/Numerol/Art3.pdf>, consultat el 12-03-2009.

GRAS-MARTí, Albert et al. «La evaluación, como ejemplo de integración de las TIC en la enseñanza». Comunicación y pedagogía, no 190 (2003), pp. 46-49.

- «Revision of prerequisites: ICT tools». AEQ-Academic Exchange Quarterly, vol. 7, no 3 (2003). <http://rapidintellect.com/AEQweb/ redpast.htm>, consultat el 25-06-2006.

HufFaKer, David A. i Calvert, Sandra L. «Gender, identity, and language use in teenage blogs». Journal of Computer-Mediated Communication, vol. 10, $\mathrm{n}^{\circ} 2$ (2005), $<$ http://jcmc.indiana.edu/vollo/issue2/huffaker.html>, consultat el 12-01-06.

LIJNSE, P. L. «Didactics of science: the forgotten dimension of science education research». En R. Millar, J. Leach i J. Osborne (Eds.), Improving science education. The contribution of research. Buckingham, Open University Press, 2000, pp. 308-326.

Lim Yuen Lie, Lisa-Angelique i Cheong, Emil. «How Do Male and Female Students Approach Learning at NUS?». CDTL Brief, vol. 7, nº 1 (2004). <http:// www.cdtl.nus.edu.sg/brief/v7n1/default.asp>, consultat el 19-10-2009.

Mcanally-Salas, Lewis i ARMIJO DE VEGA, Carolina. «La estructura de un curso en línea y el uso de las dimensiones del aprendizaje como modelo instruccional». Revista Iberoamericana de Educación (2001), <http://www.campus-oei. org/revista/deloslectores/McAnally.PDF>, consultat el 1-09-2008.

MCSPORRAn, Mae i Young, Stuart. «Does Gender Matter in Online Learning?». 4th Annual LTSN-ICS Conference, NUI Galway, 2001. <http://hyperdisc.unitec.ac. nz/research/ALTJpaper_9.pdf>, consultat el 8-06-2009.

MilachaY, Vicente Y. i GRAS-MARTí, Albert. «Instalación y gestión de plataformas virtuales para el desarrollo de Proyectos Escolares de Ciencia Internacionales». En J. Mendoza i M.A. Fernández (coords.) Educación, Enerxía e Desenvolvemento Sostible. Santiago de Compostela, ICE Universidade de Santiago de Compostela, Colección Informes e Propostas n ${ }^{\circ}$ 18, 2006, pp. 407-424.

MORA, Elizabeth. «Anàlisi de les enquestes finals de cursos tic@'t-CED». (En vies de publicació).

RICHARDSON, Helen J i FRENCH, Sheila. «Education on line: What's in it for Women?» En E. Balka i R. Smith (eds). Women Work and Computerization: Charting a course for the future. Vancouver, BC, 2000, pp. 212-216.

RuBIO, $\mathrm{M}^{\mathrm{a}}$ Cruz. «La imagen virtual de la mujer. De los estereotipos tradicionales al ciberfeminismo». Feminismos/s, nº 2 (2003), pp. 167-182.

SADLER-SMITH, Eugene. «Approaches to Studying: age, gender and academic performance». Educational Studies, vol. 22 (1996), pp. 367-379.

SEVERIENS, Sabine E., TEN DAM, Geert T. N. «Gender differences in learning styles: A narrative review and quantitative meta-analysis». Higher Education, vol. 27, $n^{\circ} 4$ (2004), pp. 487-501. 